\title{
Carga e iniciativa probatoria en acciones populares y su determinación constitucional
}

\author{
Recibido: 19 de junio de 2020 - Aprobado: 26 de julio de 2020 \\ https://doi.org/10.22395/ojum.v20n42a3
}

\author{
Juan Camilo Herrera Díaz \\ Universidad de Antioquia, Medellín Colombia \\ juan.herrera@udea.edu.co \\ https://orcid.org/0000-0002-2464-3380 \\ Juliana Pérez Restrepo \\ Universidad de Antioquia, Medellín Colombia \\ juliana.perezr@udea.edu.co \\ https://orcid.org/0000-0003-3873-5996
}

\section{RESUMEN}

El objetivo del artículo es reflexionar acerca de la carga probatoria dinámica e iniciativa probatoria del juez en el marco de la acción popular como figuras mediante las cuales, eventualmente, se lograría la protección de derechos colectivos. La metodología empleada se basó en la revisión documental y jurisprudencial. De los resultados del artículo se destaca la prevalencia de los derechos colectivos sobre ritualidades probatorias. En este sentido, se determina que si bien los accionantes deben soportar la carga de la prueba, también es cierto que el juez debe considerar las finalidades de las acciones públicas constitucionales frente a la real protección de derechos, lo que eventualmente le implicará desplegar sus facultades oficiosas en la materia. La principal conclusión hace referencia a que la parte accionante tiene la carga de la prueba en las acciones populares en dirección a demostrar los hechos afirmados, pero hace énfasis en que, en el caso concreto, la carga probatoria puede ser distribuida por diferentes razones. Igualmente, el juez se ve llamado a adelantar su deber oficioso para decretar y practicar pruebas excepcionalmente para procurarse la tutela judicial efectiva, sin que ello implique suplir las deficiencias probatorias por falta de diligencia de las partes.

Palabras clave: acción popular; carga de la prueba; carga dinámica de la prueba; defecto fáctico; derecho a la prueba; derechos colectivos; prueba de oficio. 


\title{
Burden of Proof and Probationary Initiative in Popular Claims and its Constitutional Determination
}

\begin{abstract}
The objective of the article is to reflect upon the dynamic burden of proof and the probationary initiative of the judge in the framework of the popular action as a figure through which, eventually, the protection of the collective rights might be achieved. The methodology employed was based on the documentary and jurisprudential review. One of the achievements of the article was the prevalence of collective rights over the probationary rituality. Thus, it determines that even though the claimant must provide the burden of proof, it is also true that the judge must consider the goals of the constitutional public actions towards the real protection of the rights, which will eventually imply the deployment of its officious faculties in the matter. The main conclusion refers to the fact that the claiming party has the burden of proof in the popular claims towards demonstrating the affirmed facts, but emphasizes the fact that, in the concrete case, the burden of proof might be distributed for different reasons. Likewise, the judge finds her or himself to advance its officious duty for exceptionally decreeing and performing proofs for procuring effective judicial protection without filling proof deficiencies due to a lack of diligence by the parties.
\end{abstract}

Keywords: popular action; burden of proof; dynamic burden of proof; error of fact; right to proof; collective rights; proof of office. 


\section{INTRODUCCIÓN}

Este artículo de reflexión es un producto académico de la investigación terminada Las subreglas jurisprudenciales en las providencias de la Corte Constitucional en torno al defecto fáctico, presentada ante el Centro de Investigaciones Jurídicas de la Facultad de Derecho y Ciencias Políticas de la Universidad de Antioquia y financiada por la mencionada Facultad. Tuvo como investigador principal a Juan Camilo Herrera Díaz, y como coinvestigadora a Juliana Pérez Restrepo. Dicha investigación presenta de manera sintética la doctrina constitucional colombiana respecto al error probatorio desde diferentes ángulos, así como su relación con la afectación del derecho a la prueba y con la de acción de tutela contra sentencias.

En virtud del derecho a la prueba en coherencia con el acceso a la administración de justicia, se hace alusión a la carga de la prueba y a la iniciativa probatoria por parte del juez en las acciones populares. En primer lugar, se realiza desde la perspectiva del ejercicio de dicha carga por parte del accionante en dirección a demostrar los hechos afirmados, con lo que se pretende la protección de derechos colectivos y se hace énfasis en que, en el caso concreto, la carga de la prueba puede ser distribuida por diferentes razones, sobre las cuales habrá referencia en este escrito. En segundo lugar, el juez se ve llamado a adelantar su deber oficioso para decretar y practicar pruebas excepcionalmente a fin de procurar la tutela judicial efectiva, sin que ello implique suplir las deficiencias probatorias por falta de diligencia de las partes.

En principio y en términos generales, en relación con la posición de las partes, el actor popular se encuentra en una posición de desventaja frente al accionado debido a que no tiene la carga de la prueba, lo que ubica a este último en una zona de confort porque podría limitarse a la negación de las pruebas y hechos aducidos en su contra. Con ello, se desvirtuaría el principio de lealtad procesal, pero todo ello con respecto al aporte de todas las pruebas necesarias para acreditar los hechos afirmados en la acción, las cuales en ocasiones implican altos costos. Igualmente, algunas veces los accionantes no cuentan con conocimiento jurídico. Así, aunque para la presentación de una acción popular no se requiere de representación judicial, no es descabellado suponer que la insuficiencia en tal conocimiento puede generar desequilibrio entre las partes, pues en la mayoría de los casos los accionados son entidades públicas o privadas que cuentan con asesoría o representación judicial. Por último, al defenderse un interés colectivo, no un derecho subjetivo particular y sin que ello represente retribución económica alguna, debería contemplarse cierta "flexibilidad" probatoria, pues el Estado está llamado a garantizar el interés público.

Es así como el objetivo de este artículo es reflexionar acerca de la carga dinámica de la prueba e iniciativa probatoria del juez en las acciones populares como figuras a través de las cuales, eventualmente, se lograría la protección de derechos colectivos. Y a pesar de que la carga dinámica no está expresamente preceptuada para las acciones 
populares, podría ser aplicada bajo el clásico aforismo "quien puede lo más, puede lo menos". Esto quiere decir que si el juez, bien sea por razones económicas o técnicas, puede impartir las órdenes necesarias para suplir la deficiencia y obtener los elementos probatorios indispensables para proferir un fallo de mérito en el evento en que la carga de la prueba no pueda ser cumplida, entonces también podría aplicar oficiosamente la distribución de la carga en los términos del artículo 167 del Código General del Proceso (Ley 1564, 2012), en tanto este también es un referente normativo de la acción popular para proteger derechos constitucionales de carácter público.

Ambas figuras, la carga probatoria dinámica y la prueba de oficio — que deberían tener una aplicación más activa en las acciones populares-, están relacionadas en este ámbito pues las evidencias no obtenidas a través de la distribución de la carga se podrían arrimar mediante decreto oficioso de pruebas en aras de la protección de derechos colectivos ante el estado de vulnerabilidad o desventaja de la parte accionante. Aunque en el juez no recae carga probatoria alguna, este tiene el deber jurídico de decretar pruebas oficiosamente, según sea el caso, so pena de incurrir en causal de procedencia de acción de tutela contra sentencias que ha pronunciado la Corte Constitucional, como la Sentencia T-264 (2009).

La metodología empleada para la construcción de este escrito se basó básicamente en la revisión documental y jurisprudencial, para la cual utilizaron bases de datos bibliográficas disponibles en páginas electrónicas de distintas instituciones universitarias u organismos oficiales. Casi en su totalidad, las sentencias seleccionadas para este escrito provienen de la investigación inicialmente mencionada. Para ello, se rastreó un número significativo de sentencias de la Corte Constitucional en los últimos veinte años con el objeto de identificar las subreglas jurisprudenciales empleadas por esta corporación para dirimir controversias en sede de tutela en relación con el defecto fáctico. De ahí que surgiera el interés de ampliar el espectro de garantías del derecho fundamental a la pruebal a partir del acercamiento al tema de la carga probatoria en asuntos de interés constitucional, como son los derechos colectivos y su justiciabilidad, específicamente en lo referente al ejercicio probatorio en las acciones populares. En ese sentido, para este artículo se eligieron las sentencias afines al tópico abordado, de manera que se delineara una postura constitucional en ese contexto para la protección de derechos colectivos.

El mecanismo de acción popular es un tema que, aunque es por excelencia del terreno de la jurisdicción de lo contencioso administrativo, aquí se da preeminencia a lo constitucional por su relación con los derechos a la prueba, debido proceso, acceso a la administración de justicia o tutela judicial efectiva.

De otra parte, el trámite de acción popular descrito en el tercer capítulo se seleccionó en tanto que la coautora fungió allí como actora popular. Esta experiencia

Para profundizar en este punto se puede consultar. Ruiz Jaramillo (2017). 
también ocasionó el interés para desarrollar el presente tema en tanto se considera que en dicho trámite, como se presentará, no hubo las suficientes garantías probatorias para la producción y valoración de la prueba, de modo que se permitiera el éxito de las pretensiones. Se discurre que al articular este trámite con las posturas de la Corte Constitucional, en este caso se presentó defecto fáctico.

Este artículo se compone de tres apartados. En primer lugar, se describen brevemente a partir de la doctrina los conceptos carga de la prueba y carga dinámica de la prueba. En segundo lugar se realiza una aproximación a la carga de la prueba y la prueba de oficio en las acciones populares. Por último, se trae a colación el trámite de acción popular llevada a cabo en Medellín como estudio de caso, mencionado previamente, además de algunos pronunciamientos de la Corte Constitucional frente al tema.

\section{ASPECTOS BÁSICOS DE LA CARGA DE LA PRUEBA}

En términos generales, la carga de la prueba es, por un lado, un poder de las partes de disponer de los diferentes medios probatorios para respaldar los hechos sobre los que se fundan las respectivas pretensiones o excepciones. Por otro lado, es una regla de juicio del juez, dependiendo del cumplimiento o no de dicha carga, mediante la cual forma su convencimiento y, en consecuencia, acoge o no la demanda. Chiovenda (2005) plantea que la carga de la prueba está íntimamente relacionada con el principio dispositivo en el proceso, pues la distribución de tal carga no tendría sentido en un esquema oficioso investigativo sobre la verdad de los hechos.

Según Micheli (1961) la tradición romana fundó el concepto carga de la prueba, con la base de que cada una de las partes debía alegar y probar en el proceso aquellos hechos a los cuales la norma jurídica hiciera alusión respecto del efecto deseado. La teoría de la carga de la prueba se ha erigido, entonces, en que tal carga apunta al logro de los objetivos de las partes dentro del proceso, lo que la diferencia de la carga de obligación. Así, este autor entiende que en determinados casos la norma jurídica indica la conducta que es necesaria observar para conseguir un resultado jurídicamente relevante.

Finaliza Micheli (1961) señalando que "la regla de la carga de la prueba tiene [...] como su principal destinatario al juez y su naturaleza jurídica depende, por tanto, de la del ambiente en que ella actúa, esto es, el proceso" (p. 213).

Según Parra (2007), la carga de la prueba es una regla de juicio que lleva ínsita la autorresponsabilidad de las partes para que los hechos que estas ventilan en el proceso judicial sean demostrados. En este sentido, para el juez es una herramienta que le permite fallar generalmente en contra de quien no haya ejercitado tal deber de autorresponsabilidad por no aparecer probados los hechos controvertidos. Parra (2007) reitera que la carga de la prueba no es una obligación ni un deber, pues no existe un órgano legitimado para exigir su cumplimiento. 
Entonces, la carga de la prueba no es una obligación de las partes. Pero si no es cumplida por una u otra acarreará con las consecuencias negativas según hayan sido las pretensiones o excepciones. Así, y entre otros elementos, también define Devis (2007) que dicha carga es una noción procesal que contiene la regla de juicio que le indica al juez cómo debe fallar en el evento en que este no encuentre las pruebas sobre las que debería sustentar su decisión. No cumplir con la carga probatoria puede conducir a las consecuencias desfavorables del proceso, a no ser que los hechos sean acreditados mediante pruebas aportadas por la contraparte o por el juez de manera oficiosa.

En este orden de ideas, la carga de la prueba

indica a quién corresponde evitar que falte la prueba de cierto hecho, si pretende obtener una decisión favorable basada en él, pero si el juez o la contraparte la suministran, queda cumplido el interés de quien era sujeto de tal carga y satisfecha ésta. Si es un hecho exento de prueba, no existe carga de probarlo. (Devis, 2007, p. 198)

Devis (2007) sintetiza la doble función que cumple la carga de la prueba. En primer lugar, es una regla de juicio para el juzgador que señala la ruta a seguir en caso de no encontrar los medios de prueba que fundamentarían una decisión de fondo y evita proferir un non liquet o sentencia inhibitoria, lo que convierte la carga de la prueba en sucedánea de medios de prueba. En segundo lugar, es una regla de conducta dirigida a las partes, pues les indica soslayadamente los hechos que les interesa probar para obtener lo perseguido en las pretensiones o excepciones.

Por su parte, Rosenberg (2002) manifiesta que las reglas sobre la carga de la prueba permiten al juez formarse un juicio sobre la pretensión o excepción, en tanto le indican un panorama en la construcción de la decisión, a falta de certeza en la demostración de los hechos a través de evidencias aportadas al proceso. En consecuencia, la decisión afectaría negativamente a la parte sobre la cual recaía la carga de la prueba de una afirmación de hecho no aclarada.

Y agrega:

cada parte tiene la carga de la afirmación y de la prueba con respecto a los presupuestos y las características o el estado de cosas relativos a las normas jurídicas que le son favorables, esto es, de las normas sin cuya aplicación la parte no puede tener éxito en el proceso. (Rosenberg, 2002, p. 198)

Ahora, para cerrar esta aproximación conceptual acerca de la carga de la prueba, Montero (2007) sostiene que la carga de la prueba "sólo [sic] se aplica cuando existe duda o incertidumbre de los hechos, es decir, cuando no se logró certeza respecto de los hechos controvertidos y relevante al caso por la actividad de las partes" (p. 126). 
La carga de la prueba se ha denominado como regla estática o dinámica. En primer lugar, el artículo 177 del Código de Procedimiento Civil —Decreto 1400 (1970) - establecía la carga de probar el supuesto de hecho de las normas que consagraban el efecto jurídico que las partes perseguían. La doctrina denomina lo establecido en ese artículo como regla de la carga estática de la prueba porque es fijada de manera general previa, sin que, por el hecho de que se inicie determinado proceso judicial, tenga especiales características o la regla deba ser modificada. Esto quiere decir que la regla permanece de forma estática sin importar el proceso donde la misma deba aplicarse.

Sin embargo, la regla de la carga estática de la prueba no prevé los casos difíciles en los cuales al demandante le es complejo probar determinada circunstancia como, por ejemplo, en los casos de responsabilidad médica, simulación, entre otros.

De otra parte, la regla de la carga dinámica de la prueba consiste en que debe probar los hechos aquel que se encuentre en mejores condiciones de hacerlo, bien sea por el conocimiento de los hechos, por el contacto directo que tenga con los elementos materia de prueba o por otras circunstancias como debilidad manifiesta de la parte contraria.

Pero con independencia de la posición tradicional del demandante o del demandado, habrá eventos en que la carga de la prueba se distribuirá recayendo sobre ambas partes, especialmente sobre aquella que se encuentre en mejores condiciones para producirla (Peyrano, 2008). Asimismo, tal carga es una regla que le permite al juez determinar la parte que correrá con las consecuencias adversas por la falta de prueba de acuerdo con la facilidad de una parte u otra para suministrarla (Bermúdez, 1995).

Se debe tener presente que esta teoría, según indica Peyrano (2008)

no desconoce las reglas clásicas de la carga de la prueba, sino que trata de complementarla o perfeccionarla, flexibilizando su aplicación en todos aquellos supuestos en que quien debía probar según la regla tradicional se veía imposibilitado de hacerlo por motivos completamente ajenos a su voluntad. (p. 60).

De otro lado, Peyrano (2008) expresa que en la actualidad nadie puede ignorar la plena vigencia de esta nueva doctrina, por lo cual no hay lugar a las "sorpresas" respecto de la distribución de la carga de la prueba. En este sentido, quien se encuentre en mejor posición probatoria - lo que se puede advertir previamente- - y simule distracción o asuma un actitud de simple negación, tendrá que atenerse a que la dinámica de la carga de la prueba le resulte adversa, por lo que luego no puede alegar indefensión en la medida en que se estuvo en una posición favorable para probar, pero no se hizo y se guardó silencio.

Con el dinamismo de la carga de la prueba se propende por la actitud probatoria activa de ambas partes. De esta manera, se supera la pasividad acostumbrada del 
demandado con la regla estática, bajo la cual se limita a negar las afirmaciones en su contra o a callar respecto de las mismas.

Es así que no se trata de un principio general inmutable, esto es, que se invierta la carga de la prueba de manera permanente, sino de instar a todos los contendientes a aportar todos los medios de prueba de que puedan disponer para alcanzar el conocimiento de la verdad real. De este modo, el juez podrá prescindir del principio general tradicional impuesto al demandante en relación con la prueba de la culpa del demandado. Adicionalmente, deberá prescindir de un principio general de presunción de culpa, según sea el caso concreto (Tamayo, 1993).

La regla general en la carga dinámica de la prueba consiste, entonces, en que la redistribución de la carga de probar determinados hechos se efectúa en cada caso en particular, es decir, se debe analizar cada caso en concreto. Por lo tanto, no es una regla general que se establezca de manera previa en los procesos.

En Colombia, durante la década de los noventa, la jurisprudencia del Consejo de Estado comenzó a entrever la regla de la carga dinámica de la prueba cuando, en los procesos de responsabilidad médica y bajo el sistema de falla presunta, al médico le correspondía demostrar que la ausencia de falla en el servicio - que este había prestado de manera adecuada - realmente no era dinámica, sino que para este tipo de casos hubo una inversión permanente de la carga de la prueba.

Ya para el año 2000, la teoría de la regla de la carga dinámica se recogió de manera explícita en la doctrina jurisprudencial de esta corporación, en la cual se criticaba el establecimiento de una falla presunta, y se reemplazó por el dinamismo en el sentido de establecer en cada caso concreto a qué parte se le facilitaba probar los hechos controvertidos. Esto quiere decir que si el juez advertía una grave dificultad probatoria en cabeza del actor, debía inaplicar el artículo 177 del Código de Procedimiento Civil — Decreto 1400 (1970) — para el caso concreto a fin de distribuir la carga de la prueba y de esta forma aplicar la regla de la carga dinámica de la prueba. No obstante, el Consejo de Estado determinó en la Sentencia 15772 (2006) el regreso a la falla probada, en términos simples, a la carga de la prueba tradicional.

Lo anterior presenta algunos antecedentes judiciales de la carga probatoria dinámica en Colombia. Sin embargo, tiempo después, en la época de elaboración del proyecto de Código General del Proceso, se consolidó la idea de positivizar la carga dinámica de la prueba en el ordenamiento jurídico colombiano en coherencia con el fortalecimiento jurisprudencial del derecho a la prueba. En relación con ello, se esbozó:

El derecho fundamental a la prueba implica que a ella se debe acceder sin obligar al necesitado a realizar actos de proeza o que sencillamente a pesar de tener ese derecho, le resulte imposible conseguirla, porque quien la puede desahogar es su contraparte y ésta [sic] no tiene interés en hacerlo. Frente a esta realidad y con sustento en el artículo $1^{\circ}$ de la Constitución Política que se refiere a la 
solidaridad de las personas, se consagra que cuando a una de las partes le resulte más fácil probar determinados hechos, corresponde a ella demostrarlos. (Gaceta del Congreso 119, 2011)

Este hecho afianza, entonces, el principio de lealtad procesal y presenta un desplazamiento a una especie de solidaridad. De igual manera, se enfatizó en el trámite del Código General del Proceso que la carga de la prueba debía mantener su concepción clásica. No obstante, si la contraparte tenía la facilidad de probar determinado hecho, debía hacerlo. De esta manera, se llegó a esa conclusión, en el caso concreto, a partir de las reglas de la experiencia (Gaceta del Congreso 119, 2011).

Finalmente, el Código General del Proceso (Ley 1564, 2012) introdujo dentro de su normatividad la modificación al régimen de la carga de la prueba. Así, extendió el campo de acción del operador de justicia respecto de la misma, además de que estableció elementos específicos para darle aplicación dentro del proceso jurisdiccional en cada caso concreto.

En consecuencia, el artículo 167 de esta normativa incluyó la carga probatoria dinámica, a saber:

Artículo 167.- Carga de la prueba. Incumbe a las partes probar el supuesto de hecho de las normas que consagran el efecto jurídico que ellas persiguen. No obstante, según las particularidades del caso, el juez podrá ${ }^{2}$ de oficio o a petición de parte, distribuir, la carga al decretar las pruebas, durante su práctica o en cualquier momento del proceso antes de fallar, exigiendo probar determinado hecho a la parte que se encuentre en una situación más favorable para aportar las evidencias o esclarecer los hechos controvertidos. La parte se considerará en mejor posición para probar en virtud de su cercanía con el material probatorio, por tener en su poder el objeto de prueba, por circunstancias técnicas especiales, por haber intervenido directamente en los hechos que dieron lugar al litigio, o por estado de indefensión o de incapacidad en la cual se encuentre la contraparte, entre otras circunstancias similares. (Ley 1564, 2012)

Por tanto, la carga de la prueba tuvo una amplitud en su regulación. De esta manera, el anterior artículo retomó la noción clásica de carga de la prueba establecida en el Código de Procedimiento Civil como regla general, y como excepción introdujo la posibilidad de que el juez pudiera distribuirla en la etapa de práctica de pruebas o antes de dictar sentencia. Así, instó a quela parte que se encuentre en mejores condiciones para acreditar determinado hecho aporte las evidencias respectivas.

Con la concurrencia de las reglas de la carga estática y dinámica de la prueba, se está hablando de un sistema mixto. Empero, debe aplicarse la regla de la carga estática como regla general y la carga dinámica como excepción. Así:

La decisión respectiva, de aplicar el sistema de carga dinámica, podrá adoptarse de oficio o a petición de parte, de modo que nada obsta para que en los

"Podrá": expresión declarada exequible mediante Sentencia C-086 (2016). 
escritos de intervención de los sujetos interesados, se le plantee al juez la necesidad de que para el caso específico y teniendo en cuenta sus particularidades, se aplique el sistema de carga dinámica respecto de ciertos fundamentos jurídicos. (Cruz, 2014, p. 209)

Es así como, desde la presentación de la demanda, se puede poner de presente al juez que no es posible allegar una prueba que sustente los hechos y solicitar dar aplicación a la regla de la carga dinámica de la prueba para que sea la contraparte quien deba allegar lo solicitado. En el evento en que el juez decrete mediante auto una prueba con la regla de la carga dinámica de la prueba, tal auto puede ser impugnado solamente mediante recurso de reposición.

En síntesis, la carga de la prueba — sea en el caso concreto estática o dinámicano es una obligación, esto es, si no se cumple no habrá más sanción jurídica que las consecuencias negativas derivadas de no haberla ejercitado frente a las resultas del proceso. Además, es una regla de juicio para que el juez evite fallos inhibitorios. De otro lado, el dinamismo de la carga de la prueba podría permitir mayor eficiencia en la búsqueda de la verdad procesal al provocar una mayor actividad probatoria de las partes.

\section{LA CARGA DE LA PRUEBA EN LA ACCIÓN POPULAR}

La acción popular es la garantía constitucional prevista en el ordenamiento jurídico colombiano para la defensa de los derechos e intereses colectivos, señalados de manera no taxativa en el artículo 4 de la Ley 472 (1998). Entre las principales características de esta acción se pueden mencionar: i) es el mecanismo constitucional de protección de los derechos colectivos; ii) es una acción pública, por lo que dota a todas las personas de un instrumento destinado a la protección y garantía de los derechos colectivos; iii) procede con la sola amenaza o riesgo de que se produzca una vulneración de derechos colectivos, por ser de naturaleza preventiva; iv) tiene carácter restitutorio dada su finalidad de restablecimiento del uso y goce de los derechos colectivos (Sentencia T-443, 2013).

El actor popular tiene la carga de probar la amenaza o vulneración de los derechos colectivos invocados. Para la acción popular dicha carga está prevista en el artículo 30 de la Ley 472 (1998), por medio de la cual se desarrolla el artículo 88 de la Constitución Política de Colombia (1991) en relación con el ejercicio de las acciones populares y de grupo. El artículo 30 de la Ley 472 (1998) afirma:

Artículo 30. Carga de la prueba. La carga de la prueba corresponderá al demandante. Sin embargo, si por razones de orden económico o técnico, si dicha carga no pudiere ser cumplida, el juez impartirá las órdenes necesarias para suplir la deficiencia y obtener los elementos probatorios indispensables para proferir un fallo de mérito, solicitando dichos experticios probatorios a la entidad pública cuyo objeto esté referido al tema materia de debate y con cargo a ella. 
En el evento de no existir la posibilidad de allegar la prueba respectiva, en virtud de lo establecido en el inciso anterior, el juez podrá ordenar su práctica con cargo al Fondo para la Defensa de los Derechos e Intereses Colectivos.

Este es el único referente que trae la citada ley sobre la carga probatoria, en la cual se indica indirectamente la posibilidad de invertir dicha carga cuando el juez encuentre que por motivos de orden económico o técnico existen dificultades para obtención y práctica de pruebas que se consideran fundamentales para fallar. Esto quiere decir que el actor popular debe probar los hechos, acciones u omisiones aducidas en la demanda como constitutivas de la afectación de determinados derechos colectivos, para cuya protección ejerce la acción popular. Pero de esta carga se puede sustraer el actor cuando existan razones de orden técnico o económico que impidan acceder al medio probatorio y que estén acreditadas dentro del trámite.

En otras palabras, el actor debe probar los hechos, acciones u omisiones que, a su juicio, constituyen la amenaza o violación de los derechos colectivos aducidos, y no debe limitarse a invocar la presunta afectación de tales derechos sin demostrar los supuestos fácticos presentados en la acción popular.

Asimismo, establece el artículo 44 de la Ley 472 (1998):

En los procesos por acciones populares se aplicarán las disposiciones del Código de Procedimiento Civil y del Código Contencioso Administrativo dependiendo de la jurisdicción que le corresponda, en los aspectos no regulados en la presente Ley, mientras no se oponga a la naturaleza y a la finalidad de tales acciones.

Por expresa remisión, en lo no regulado se aplicará el actual Código General del Proceso (Ley 1564, 2012) en materia de carga de la prueba, el cual se la carga dinámica cuando se den los supuestos fácticos que lleven a configurarla. En igual sentido, el artículo 306 del Código de Procedimiento Administrativo y de lo Contencioso Administrativo afirma: "En los aspectos no contemplados en este Código se seguirá el Código de Procedimiento Civil en lo que sea compatible con la naturaleza de los procesos y actuaciones que correspondan a la Jurisdicción de lo Contencioso Administrativo" (Ley 1437, 2011).

Ahora bien, jurisprudencialmente la Corte Constitucional ha decantado a través de sus providencias la aplicación de la carga de la prueba en las acciones populares. De esta manera, en Sentencia C-215 (1999) puntualizó que la carga de prueba que recae sobre el actor no inhibe al juez del deber de emplear su facultad probatoria oficiosa cuando, por razones económicas o técnicas, el accionante no pueda aportar ciertas pruebas indispensables para adoptar un fallo de mérito.

En este contexto, se puede establecer que cuando el accionante no cuente con elementos suficientes que permitan aportar pruebas en el trámite de la acción popular, lo que debe quedar acreditado, el juez tiene el deber de decretarlas para salvaguardar los derechos colectivos de las personas que se encuentran en indefensión. 
En términos similares se pronunció el Consejo de Estado en la Sentencia AP-0117801 (2010). En esta se afirma que si por razones económicas o técnicas la carga de la prueba no puede ser cumplida por el demandante, el juez debe impartir las órdenes que se requieran para suplir los vacíos probatorios con el propósito de arrimar los medios de prueba imperiosos para producir un fallo de mérito y, de ser necesario, ordenar su práctica con cargo al Fondo para la Defensa de los Derechos e Intereses Colectivos.

Adicionalmente, el derecho a probar interpela las excesivas ritualidades, así lo hace notar Rojas (s. f.):

Recuérdese el paradigma constitucional: "el derecho a la utilización de los medios de prueba pertinentes para la defensa como una de las garantías básicas del proceso", por lo que en nuestro medio se abre paso considerar que el derecho a la prueba se erige en garantía de protección de los derechos fundamentales sustanciales, a punto de que el juez tiene el poder de variar las reglas de la carga de la prueba en procura de la efectividad de los derechos sustanciales.

Nótese que de acuerdo con lo normado frente a las acciones populares, cualquier persona puede interponerlas sin que sea necesario que conozca profusamente de derecho sustancial ni procedimental, ni que sea requerida su representación judicial. Estas reglas, como la carga de la prueba, hacen que sea nugatorio el derecho predicado en ocasiones en las que las formalidades prevalecen sobre lo sustancial.

A este respecto, se indica en la Sentencia T-429 (2013):

Por otra parte el tutelante insinúa que el Tribunal efectuó una inadecuada distribución de la carga demostrativa [... ]. En ese sentido, advierte que a su modo de ver la carga probatoria debe ser diferencial en esta clase de controversias jurisdiccionales [...]. No obstante, asevera que el Tribunal desconoció esa distribución equitativa de la carga probatoria, al haber considerado que para poder amparar los derechos colectivos invocados, el actor popular tenía la carga de evidenciar "con claridad la longitud y los límites exactos del tramo vial que necesita adecuación de las aceras".

Se hace evidente que en este caso el Tribunal Administrativo de Antioquia no acogió las pretensiones por unas medidas longitudinales que el accionante no indicó. Esta cuestión pudo ser subsanada mediante el decreto oficioso de prueba pericial, por ejemplo, a través de las razones que llevaron a la Corte Constitucional a dejar sin efectos la decisión tomada por ese tribunal, dado que tales motivos no implicaban la negativa para salvaguardar los derechos afectados a toda una comunidad (más adelante se detallará este caso). Además, esta postura ya había sido sentada en la Sentencia C-215 (1999).

Un caso similar en el que la Corte Constitucional manifestó que se había vulnerado el debido proceso - teniendo en cuenta que el "juez que conoce de una acción popular que involucra garantías fundamentales de sujetos de especial protección constitucional, debe observar además un particular cuidado en el análisis 
del caso que debe decidir"-, se presentó en la Sentencia T-010 (2011), la cual se retomará en el último acápite.

Estas consideraciones pueden concordar con planteamientos según los cuales, el juez, como director del proceso, puede exhortar, recomendar o prevenir una eventual vulneración o zanjar una afectación efectiva de derechos colectivos sin que ello se entienda como un capricho del juez constitucional. Consiguientemente, el amplio poder oficioso del juez en la defensa de los derechos colectivos es un elemento esencial de las acciones populares. Además, el juez de acción popular puede ir más allá de lo pedido por el actor, pues en todo caso la finalidad de tal mecanismo no es proteger a este, sino resguardar los derechos colectivos de toda una comunidad. En ese sentido, si resulta necesario, el juez deberá proferir fallos ultra y extra petita (Sentencia T-443, 2013).

Por último, esto lo refuerza la Corte en la Sentencia T-176 (2016) a través de la cual se esboza que, en caso de que el juez identifique como probado un hecho transgresor que no había sido alegado específicamente por el accionante, deberá tomar medidas para hacerlo cesar. A su vez, a partir de sus facultades oficiosas, el juez podrá ordenar remedios que excedan las pretensiones inicialmente formuladas, siempre que resulte necesario para purgar la vulneración o amenaza.

Es así como la carga dinámica probatoria y la prueba de oficio pueden eventualmente salvaguardar derechos colectivos protegidos por la Constitución nacional, para lo cual el juez debe remover obstáculos, en ocasiones excesivamente formalistas, con el fin de cumplir con los preceptos del Estado social de derecho que pregona el preámbulo de la carta política colombiana.

\section{APUNTES SOBRE CARGA E INICIATIVA PROBATORIA EN FALLOS JUDICIALES}

En este apartado se referencian extractos de algunos presupuestos de sentencias de la Corte Constitucional, pero antes se reflexiona acerca de un caso concreto que se basa en una acción popular interpuesta en 2011 contra el municipio de Medellín y empresas de transporte público por las máquinas contabilizadoras de buses y colectivos que aún hoy impiden el ingreso y la circulación en su interior de los pasajeros en condiciones de bienestar. Sobre este caso se hará un recuento de la actuación procesal surtida y los argumentos expuestos en primera y segunda instancia para no amparar los derechos colectivos invocados.

El 12 de diciembre de 2011 la demandante, obrando en nombre propio, presentó acción popular en contra de la Secretaría de Transportes y Tránsito de Medellín —-hoy Secretaría de Movilidad - y las sociedades particulares denominadas Transportes Castilla S. A. y Transportes Medellín S. A. Este caso le correspondió por reparto al Juzgado 17 Administrativo del Circuito de Medellín, el cual, mediante providencia del 
día siguiente, admitió la acción —radicado No. 05001-33-31-017-2011-00694-00—y ordenó efectuar las notificaciones y vincular a la nación-Ministerio de Trasporte.

Los derechos colectivos invocados fueron: i) derecho a la buena calidad de bienes y servicios; ii) derechos de los consumidores y usuarios; iii) derecho de acceso a los servicios públicos y a que su prestación eficiente y oportuna; y iv) derecho a la accesibilidad de las personas en situación de discapacidad.

Mediante la acción se pretendía que i) se adoptaran las medidas técnicas dirigidas a acondicionar los buses y colectivos de transporte público, de tal forma que se modificara el mecanismo de contabilización de pasajeros y se sustituyera por uno diferente que no afectara la dignidad de las personas, sino que, por el contrario, garantizara los derechos colectivos invocados; ii) se ordenara al municipio de Medellín, a través de la Secretaría de Tránsito y Transportes, ejercer los controles suficientes tendientes a la adecuada implementación de la medida; y, subsidiariamente, iii) se ordenara el desmonte de las máquinas registradoras de buses y colectivos de transporte público.

Como hechos se planteó i) que en la ciudad de Medellín los buses y colectivos habían cambiado sus dispositivos de contabilización de pasajeros aproximadamente hacía dos años; ii) que cuando ese nuevo mecanismo había comenzado a funcionar no se hicieron esperar las reacciones de malestar de los pasajeros, dadas las restricciones de acceso a los vehículos para la comunidad en general; y iii) que el sistema de registradoras exponía permanentemente a las personas a maltratos físicos, incomodidades y accidentes.

Las entidades demandadas en la contestación manifestaron su oposición frente a las pretensiones y, por lo tanto, solicitaron que se desestimaran. De las distintas contestaciones se resalta: i) las empresas transportadoras casi se limitaron a expresar que los dispositivos de contabilización de pasajeros habían sido importados hacía cinco años, que tal transacción había cumplido con todos los requerimientos legales y a un alto costo, y que desde la instalación de los mismos no habían recibido queja alguna de los usuarios ni se habían iniciado investigaciones por parte de los entes de control; y ii) el Ministerio Público arguyó que no había norma que posibilitara la implementación de las cajas registradoras en discusión. En consecuencia, si se había cuestionado el sustrato legal de dichos dispositivos lo connatural era aceptar su desmonte.

Posteriormente, se convocó a audiencia de pacto de cumplimiento. Empero, no se pudo llevar a cabo en razón a la inasistencia del representante del municipio de Medellín. El día 9 de noviembre de 2012 se decretaron las pruebas documentales ${ }^{3}$ y testimoniales solicitadas por las partes. Sin embargo, se negó la inspección judicial

3 La parte accionante aportó copias de derechos de petición y respuestas de los mismos, dentro de las cuales se evidenciaban multiplicidad de quejas respecto de las registradoras, tanto por la incomodidad y falta de accesibilidad adecuada como por el peligro que representaban, dado que por ellas se podía ingresar pero no salir, lo que suponía una salida menos en caso de emergencia. 
solicitada por la parte accionante con el argumento de que en la solicitud de tal inspección no se indicaba expresamente el objeto a ser inspeccionado, a sabiendas de que el centro del conflicto jurídico eran ciertamente las máquinas registradoras.

En Sentencia 58 (2013), de la valoración probatoria, es importante señalar que el juez adujo que en las fotografías no se indicaba quien había sido el autor, con qué fines se habían obtenido ni la fecha de su registro, por lo que no le dio valor probatorio alguno a las mismas.

Seguidamente, el titular del despacho concluyó:

Los medios probatorios allegados al proceso no permiten establecer la acción u omisión en que incurre la entidad territorial y la empresa particular accionada al tener instalados los mecanismos de contabilización de pasajeros, denominados como registradoras.

Así mismo, esos medios no acreditan la forma en que los usuarios y consumidores ven afectados sus derechos, puesto que sólo [sic] se cuenta con quejas específicas de las que se mencionan situaciones hipotéticas que pueden llegar a ocurrir, pero que no tienen relación directa con el uso de tales dispositivos, ni se cuenta con un medio que indique o muestre que esos dispositivos generan riesgos a los usuarios del trasporte público de pasajeros.

El acervo probatorio obrante dentro del proceso no da cuenta de la forma en que las personas en condiciones de movilidad reducida ven afectados sus derechos por la utilización de los dispositivos cuestionados.

Las pruebas no generan convicción con respecto a que el derecho a la buena calidad de bienes y servicios, la eficiente y oportuna prestación de los servicios públicos, se vea vulnerado por la utilización de las máquinas registradoras, por lo tanto no puede atenderse la reclamación formulada en ese sentido por la actora.

En conclusión, ninguno de los medios de prueba aportados da cuenta de la afectación de los derechos colectivos invocados por la actora popular, lo que implica que los presupuestos para que prospere la acción popular no están acreditados y en consecuencia lo procedente será negar el amparo constitucional solicitado. (Sentencia 58, 2013)

Por ello, la decisión de primera instancia no amparó los derechos colectivos planteados, al igual que el Tribunal Administrativo de Antioquia (mediante Sentencia 232, radicado No. 05001-33-31-017-2011-00694-01). Cuando el día 8 de octubre de 2013 confirmó la decisión proferida por el ad-quo sin mayores variaciones, casi se limitó a reproducir los argumentos.

Es importante expresar que los afectados por el problema jurídico señalado en esta acción popular comprenden muchos grupos poblaciones, como las personas en situación de discapacidad permanente o transitoria, con obesidad o de talla baja, mujeres en estado de gestación o con menores en brazos, adultos mayores, etc., por 
lo que se puede decir que la mayoría tienen protección especial por la Constitución Política de Colombia de 1991. Ahora bien, no se comprende por qué el juez de primera instancia desestimó la inspección judicial sin argumento valedero, de acuerdo con lo enunciado en la sentencia y teniendo en cuenta que pudo llegar a ser una prueba que respaldaba las fotografías presentadas por la accionante.

De otra parte, se puede evidenciar que la iniciativa oficiosa de ambos órganos jurisdiccionales fue nula, ya que no decretó pruebas de oficio para suplir la deficiencia probatoria - verbigracia, un perito especialista en el tema, para que rindiera un dictamen que ayudara a dilucidar muchos planteamientos de la accionante, aun cuando se solicitó que los gastos a futuro derivados de la actividad probatoria fueran sufragados por el Fondo para la Defensa de los Derechos e Intereses Colectivos, previsto en el artículo 19 de la Ley 472 (1998)—, como era su deber constitucional. Más aún hay que tener en cuenta que se trataba de una acción popular, así como las características de esta garantía constitucional y la naturaleza de los derechos que protege. Por otra parte, no distribuyó la carga de probar en el entendido de vislumbrar que, por las particularidades del caso, los accionados estaban en una situación más favorable para aportar medios de prueba con respecto de los hechos controvertidos, en virtud de su cercanía con el material probatorio y por las circunstancias técnicas especiales. Inclusive, sigue siendo tan evidente que estas cajas registradoras se configuran como barreras de accesibilidad que se podría argumentar, eventualmente, respecto de la prueba, un hecho notorio, el cual estaría exento de prueba. Por lo cual, en últimas, se considera que en este caso se presentó defecto fáctico por las consideraciones anteriormente señaladas.

A continuación, habrá una aproximación a dos sentencias ya mencionadas de la Corte Constitucional, en específico, acerca de presupuestos fácticos y breves consideraciones adicionales de las ya descritas de esta corporación frente al tema probatorio.

Sentencia T-010 (2011)

La Fundación para la Protección de los Intereses y Bienes Difusos y el Medio Ambiente (Proteger) interpuso una acción popular contra Inversiones Hoteleras Rosales S. A., propietaria del establecimiento de comercio Hotel Rosales Plaza ubicado en Bogotá, por no garantizar accesos adecuados para las personas en situación de discapacidad y por haber invadido con un local comercial el espacio público. En dicha acción popular se solicitó que se ordenara la construcción de estructuras necesarias que garantizaran la accesibilidad en igualdad de condiciones a los espacios abiertos al público y evacuar el espacio público invadido.

El juez de primera instancia concedió el amparo relacionado con la adecuación del acceso. La decisión fue apelada por ambas partes. Posteriormente, la Sala Civil del Tribunal Superior del Distrito Judicial de Bogotá revocó el fallo de instancia por 
considerar que solo las edificaciones destinadas a la prestación de servicios públicos estaban obligadas a proveer la accesibilidad de todas las personas.

En referencia a la pretensión relacionada con la ocupación del espacio público, el tribunal la negó aduciendo que las fotografías que reposaban en el expediente no acreditaban dicha ocupación por la carencia de fecha en las mismas, esto es, la fecha de su registro.

Contra las anteriores providencias, la entidad accionante interpuso acción de tutela argumentando la vulneración de los derechos a la igualdad, al debido proceso y al acceso a la administración de justicia. Se manifestó que de las fotografías resultaba evidente la ocupación permanente de dicho espacio y, a pesar de ello, el tribunal negó la pretensión sin la motivación respectiva.

La Corte Constitucional, luego de haber seleccionado el caso para su revisión, afirmó que si bien las fotos no daban certeza de la ocupación del espacio público, originaban una duda razonable sobre una eventual infracción, lo que obligaba al juez a decretar pruebas oficiosamente para determinar la vulneración o no del derecho colectivo alegado. Este deber de iniciativa probatoria tampoco fue ejecutado.

En consecuencia, la Corte Constitucional revocó el fallo de segunda instancia proferido por la Sala de Casación Laboral de la Corte Suprema de Justicia, y confirmó parcialmente la providencia proferida por la Sala de Casación Civil de la Corte Suprema de Justicia. Mediante esta se concedió la tutela del derecho fundamental al debido proceso y dejó sin efectos la sentencia dictada por la Sala Civil del Tribunal Superior del Distrito Judicial de Bogotá al sustentar que en el fallo cuestionado se había dado a las normas aplicables un alcance que se apartaba abiertamente de la voluntad del legislador.

Para ello, la Corte Constitucional ordenó proferir una nueva sentencia para corregir la omisión atinente a la ocupación o no del espacio público. En esa lógica, el tribunal accionado debía valorar todas las pruebas aportadas al proceso y ordenar la práctica de otras para esclarecer la vulneración o no del derecho colectivo.

Sentencia T-429-13 (2013)

El señor Luis Fernando Gallego Holguín interpuso acción de tutela contra el Tribunal Administrativo de Antioquia, al exponer que el fallo emitido en un trámite de acción popular le violó sus derechos fundamentales a la dignidad humana y al debido proceso. Arguyó, entre otras cosas, que el tribunal había valorado de forma inapropiada dos medios de prueba obrantes en el expediente y motivó de manera indebida sus conclusiones probatorias. La acción popular se interpuso en contra del municipio de Sabaneta para la protección de los derechos al espacio público, a la locomoción y a la seguridad dada la carencia de andenes en los barrios María Auxiliadora y Palenque de dicho municipio. 
Posteriormente, el Juzgado Trece Administrativo del Circuito de Medellín concedió la acción popular, fallo que fue impugnado. Pasó luego a la Sala Primera de Decisión del Tribunal Administrativo de Antioquia que, sin decretar la práctica de pruebas, resolvió revocar la decisión de primera instancia y denegar las pretensiones a partir de la argumentación de deficiencia probatoria.

Empero, la Corte Constitucional, en sede de revisión, señaló que el tribunal había incurrido en defecto fáctico al omitir la práctica oficiosa de pruebas necesarias para establecer con certeza los tramos viales carentes de andenes, así como los demás elementos relevantes. En definitiva, la Corte Constitucional señaló que tal defecto se traducía en la vulneración de derechos fundamentales gracias a la decisión judicial que se catalogó como abiertamente contraria a la ley y a los precedentes jurisprudenciales del Consejo de Estado y de la propia Corte Constitucional. Según estos, el órgano jurisdiccional que tramita una acción popular debe hacer uso de sus poderes probatorios oficiosos en aras de garantizar la protección y goce de los intereses y derechos colectivos.

En consecuencia, la Corte concedió la tutela y le ordenó al Tribunal Administrativo de Antioquia pronunciarse nuevamente teniendo en consideración todas las pruebas obrantes en el expediente. De ser necesario, también concedió decretar y practicar otras pruebas para un fallo de fondo respecto de la vulneración o no de los derechos colectivos al espacio público, locomoción y seguridad pública, invocados por el actor popular.

En últimas, se puede relievar que si bien el actor popular tiene la carga de probar el supuesto de hecho de las normas que consagran el efecto jurídico que persigue, en tratándose de intereses comunes y mediante lo cual no se persigue una indemnización, el juez en virtud de los poderes conferidos por el ordenamiento jurídico, como son sus poderes oficiosos para la obtención y práctica de pruebas y la inversión de la carga de la prueba en un momento y caso determinado, tiene el deber-obligación de desplegar todas las acciones encaminadas a la protección de tales derechos.

\section{CONCLUSIONES}

La carga dinámica de la prueba es una figura aplicable en la acción popular, en cuanto el juez verifique que la parte accionada se encuentra en mejores condiciones de probar los hechos objeto de controversia.

Se considera que la regulación mixta de la carga de la prueba, según el artículo 167 del Código General del Proceso (Ley 1564, 2012), es importante porque permite solucionar situaciones difíciles en la cuestión probatoria, pero se debe tener en cuenta que hay situaciones que aún faltan por regular y, por lo tanto, harán que su aplicación pueda enfrentar obstáculos hasta que no se den mayores desarrollos jurisprudenciales. 
La acción popular como acción pública constitucional, que tiene como fin la defensa de derechos e intereses colectivos y no pretensiones subjetivas, procura superar la afectación de bienes jurídicos que comprometen la existencia y desarrollo de la colectividad misma, es decir, hacer valer el interés público.

Por razones de equidad y disposición probatoria en las acciones populares, y estableciéndose así en el trámite, las entidades públicas o privadas deberían demostrar que no han incumplido el ordenamiento jurídico, sea por acción o por omisión, pues como organizaciones deben procurar el cumplimiento de la Constitución, la ley y demás normas vinculantes. En muchos casos estas entidades poseen el conocimiento profesional, técnico y hasta científico para explicar lo debatido en determinada acción. Así, por estar en mejores condiciones para probar debería aplicarse la carga dinámica probatoria. Por otro lado, si se identificara que quien se encontraba en mejores condiciones para aportar los medios de prueba era la parte accionante, entonces esta correría con los efectos negativos de la sentencia al no haber suministrado las pruebas respectivas.

El juez como director del proceso tiene que adoptar las medidas necesarias para establecer la variación de la carga de la prueba en situaciones de dificultad probatoria. Este hecho permitiría, según las reglas de este dinamismo, una mayor probabilidad de producirse decisiones de fondo, y no por la mera aplicación "sucedánea" de la carga de la prueba tradicional.

Debe analizarse durante el trámite de las acciones populares las rígidas reglas probatorias, toda vez que debe imperar la prevalencia de los derechos sustanciales sobre las formas.

El derecho a la prueba se manifiesta desde la óptica del deber del juez de decretar pruebas de oficio. Esta iniciativa probatoria tiene un papel trascendental en su tarea de preservar los valores de justicia y verdad, haciendo énfasis aquí en los trámites de acción popular. En caso de omitirse tal iniciativa, estando el juez en la obligación de ejecutarla, incurriría en defecto fáctico, causal de procedencia de tutela contra sentencia. El derecho a probar también se vería reflejado en caso de inversión probatoria, en el sentido de que los medios de prueba aportados en este contexto tendrían que surtirse, en las fases de práctica y valoración, dentro de parámetros constitucionales y legales.

Aunque jurisprudencialmente no se reconoce, bien podría considerarse que un juez podría incurrir en defecto fáctico al no invertir la carga de la prueba en un caso concreto, en los términos del artículo 167 de Código General del Proceso (Ley 1564, 2012). Esto quiere decir que cuando la parte demandada no distribuye o traslada tal carga, a pesar de advertir que se encuentra en una situación más favorable para aportar 
las evidencias o esclarecer los hechos controvertidos, falla mediante la aplicación frívola de la regla de juicio tradición al de la carga probatoria.

Si es posible fallar ultra petita y extra petita, en el supuesto de que el actor popular no identifique con suficiencia las circunstancias que dan origen al desconocimiento del derecho colectivo y el juez advierte como probado un hecho transgresor que no había sido alegado específicamente por el accionante ante el cual debe adoptar una determinación para hacerlo cesar, entonces también debería adoptar una posición activa respecto de la inversión de la carga de la prueba y del decreto oficioso de pruebas para proteger tanto los derechos colectivos como el derecho a la prueba y de acceso a la administración de justicia.

Es evidente que, sin que se pretenda suplir la carga de la prueba del actor popular, la Corte Constitucional señala que los jueces deben desplegar las herramientas que les ofrece el ordenamiento jurídico para lograr la tutela judicial efectiva teniendo en cuenta que la acción popular no tiene un afán indemnizatorio, sino la protección de derechos colectivos que involucran el interés público.

\section{REFERENCIAS}

Bermúdez, M. (1995). El futuro de la carga de la prueba en materia de responsabilidad. Revista Temas Jurídicos, 11, 16-38.

Chiovenda, G. (2005). Instituciones de Derecho Procesal Civil. Valletta Ediciones.

Cruz, H. (2014). El proceso civil a partir del Código General del Proceso. Universidad de los Andes.

Congreso de la República de Colombia. (2011, 18 de enero). Ley 1437 de 2011. Código de Procedimiento Administrativo y de lo Contencioso Administrativo. Diario Oficial n. ${ }^{\circ} 47.956$.

Congreso de la República de Colombia. (2012, 12 de julio). Ley 1564 de 2012. Código General del Proceso. Diario Oficial n. ${ }^{\circ} 48.489$.

Congreso de la República de Colombia. (1998, 05 de agosto). Ley 472 de 1998. Por la cual se desarrolla el artículo 88 de la Constitución Política de Colombia en relación con el ejercicio de las acciones populares y de grupo y se dictan otras disposiciones. Diario Oficial n. ${ }^{\circ} 43.357$.

Consejo de Estado (2006, 31 de agosto). Sentencia 15772 (Ruth Stella Correa Palacio, M. P.).

Consejo de Estado (2010, 18 de marzo). Sentencia AP-01178-01 (Marco Antonio Velilla Moreno, M.P.).

Constitución Política de Colombia [Const.] (1991). Recuperado de: http://www.secretariasenado.gov. co/senado/basedoc/constitucion_politica_1991.html

Corte Constitucional (1999, 14 de abril). Sentencia C-215-99 (Martha V. Sáchica de Moncaleano, M.P.).

Corte Constitucional (2009, 03 de abril). Sentencia T-264-09 (Luis Ernesto Vargas Silva, M.P.).

Corte Constitucional (2011, 14 de enero). Sentencia T-010-11 (María Victoria Calle Correa, M.P.).

Corte Constitucional (2013, 10 de julio). Sentencia T-429-13 (María Victoria Calle Correa, M.P.).

Corte Constitucional (2013, 11 de julio). Sentencia T-443-13 (Jorge Ignacio Pretelt Chaljub, M.P.). 
Corte Constitucional (2016, 24 de febrero). Sentencia C-086-16 (Jorge Iván Palacio Palacio, M.P.).

Corte Constitucional (2016, 11 de abril). Sentencia T-176-16 (Gloria Stella Ortiz Delgado, M.P.).

Devis, H. (2007). Compendio de la Prueba Judicial. Rubinzal-Culzoni Editores.

Gaceta del Congreso (2011). Exposición de motivos al proyecto de ley 196 de 2011, Cámara de Representantes, "por medio de la cual se expide el Código General del Proceso y de dictan otras disposiciones". Gaceta n. ${ }^{\circ} 119$.

Juzgado 17 Administrativo del Circuito de Medellín (2011, 12 de diciembre). Acción Popular Radicado n. ${ }^{\circ}$ 05001-33-31-017-2011-00694-00.

Juzgado 17 Administrativo del Circuito de Medellín (2013, 22 de abril). Sentencia n. ${ }^{o} 58$ de 2013. (Juan Guillermo Cardona Osorio, Juez).

Micheli, G. (1961). La Carga de la Prueba. Jurídicas Europa-América.

Montero, J. (2007). La Prueba en el Proceso Civil. Editorial Aranzadi S.A.

Parra, J. (2007). Manual de Derecho Probatorio. Librería Ediciones del Profesional Ltda.

Peyrano, J. (2008). Cargas Probatorias Dinámicas. Rubinzal-Culzoni Editores.

Presidencia de la República de Colombia. (1970, 06 de agosto). Decreto 1400 de 1970. Código de Procedimiento Civil. Diario Oficial n. ${ }^{0} 33.150$.

Rojas, A. (s.f.). La carga dinámica de la prueba en la jurisprudencia de la Corte Constitucional. Consultado el 10 de agosto de 2020. https://letrujil.files.wordpress.com/2013/09/37alberto-rojas-rios.pdf

Rosenberg, L. (2002). La carga de la Prueba. B DE F.

Ruiz Jaramillo, L. B. (2017). El derecho constitucional a la prueba y su configuración en el Código General del Proceso colombiano [tesis doctoral, Universitat Rovira I Virgili]. Dialnet. http://repositori.urv.cat/ fourrepopublic/search/item/TDX\%3A2745

Tamayo, J. (1993). Responsabilidad civil médica en los servicios de salud. Biblioteca Jurídica Dike.

Tribunal Administrativo de Antioquia (2013, 08 de octubre). Sentencia n. ${ }^{\circ} 232$ de 2013 (Rafael Darío Restrepo Quijano, M.P.). 